\title{
The Goo Tolerance Index: a foolproof method for choosing a medical specialty
}

$\mathrm{F}$ or most of us the holiday season is a time of good cheer - a time for feasts and merrymaking and good old-fashioned unbridled consumerism. But for senior medical students it is also a time of hand wringing and sleepless nights. Yes, for those of you who have forgotten the pain, the annual ritual of the CaRMS (Canadian Residency Matching Service) match is upon us. Applications and curricula vitae have been sent out, reference letters have been written, interviews are being arranged, and clinical clerks across the land are wrestling with the question: "What am I going to do with the rest of my life/next year?"

I vividly remember the trauma of my own CaRMS experience: navigating the match and not at all sure what I wanted to be when I grew up, I became paranoid and applied for pretty much everything everywhere. A friend of mine even tried to convince me to apply for a urology training position.

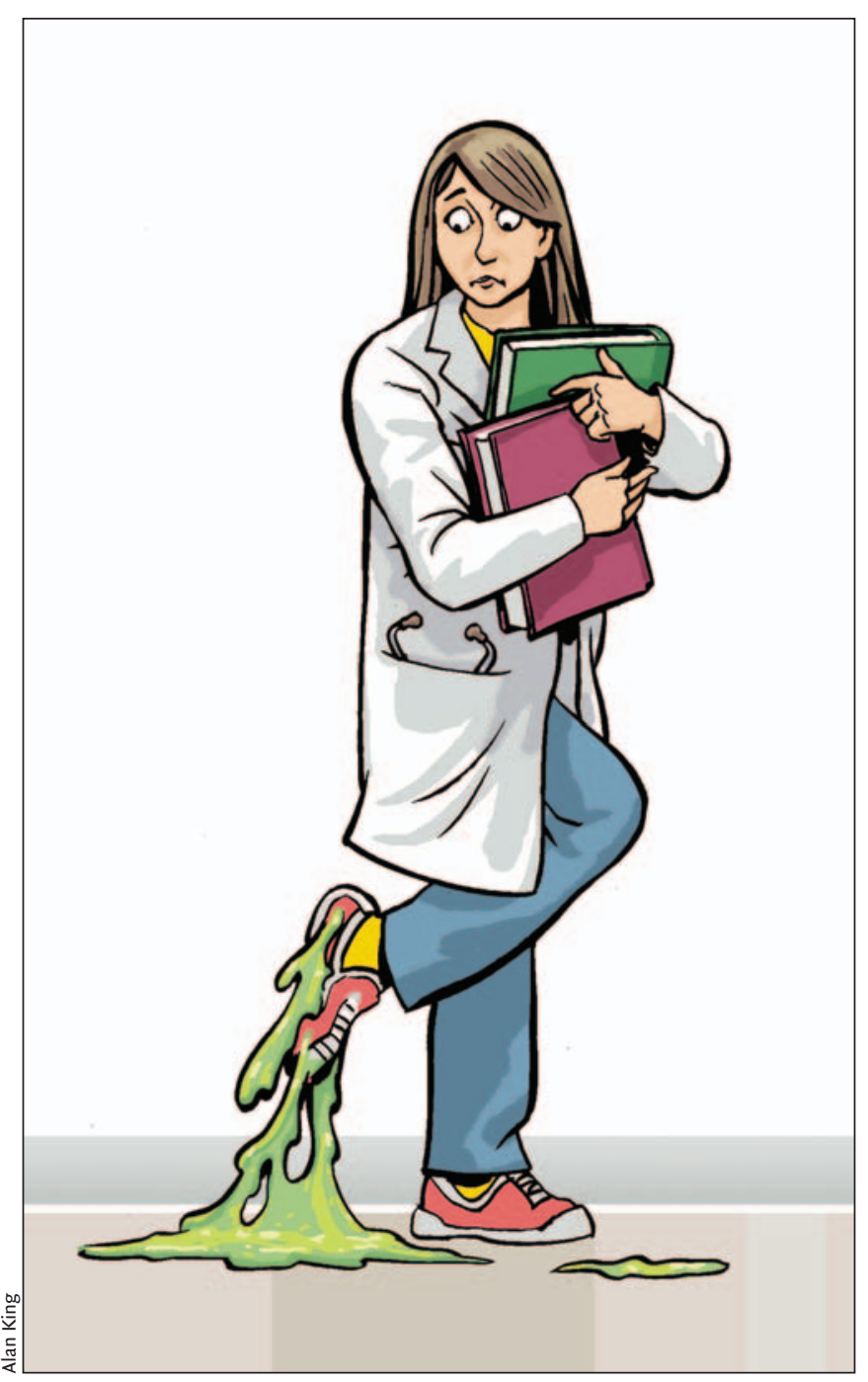

"You might have to stand around in pee all day," he said, "but at least you get to do it in expensive Italian loafers."

"Thanks," I replied, "but I'd rather have shoes that are cheap and don't stink."

But his comment planted the seed of an idea in my head, which I have since developed into a foolproof method for helping medical students choose the right specialty. I call it the Goo Tolerance Index. It is based on 3 basic premises, all of which are founded on rigorous scientific research (or at least I asked around, and everyone seemed to think they were pretty cool):

I. The practice of medicine involves a lot of goo.

2. Goo is yucky.

3. Tolerance to goo is as good a predictor as any of what specialty one is suited for.

This is how the index works: Students are first prompted to rate their own goo tolerance on a scale of I-Io. They then consult my patented Gooiness Reference of Selected Specialties Scale (GROSSS - see next section) to find their match with an appropriate specialty. For example, because my own goo tolerance is close to zero, I chose psychiatry - a specialty where patients generally stay on their side of the desk and are never touched below the waist. (On those rare occasions when things do get gooey, the psychiatrist simply calls for a nurse or sends the patient back to his or her family physician.)

\section{Gooiness Reference of Selected Specialties Scale (GROSSS)}

\section{Low-goo specialties (score 1-3)}

\section{Psychiatry}

Very little goo is involved, unless you count emotional goo.

\section{Radiology}

Practically goo-free. You get to sit around in a sterile office all day looking at pictures of goo, but you never have to touch it. Your Italian loafers do not get stinky.

\section{Neurology}

You do have to touch people, but most of the time their bodily fluids are not leaking all over you. (If they are, call the neurosurgeon.)

\section{Moderate-goo specialties (score 4-6)}

Family medicine

Lots of mucus, earwax and toe jam, with an occasional smattering of pus and vomit. Overall, though, the goo tends to be stable and relatively odour-free. Also, it is interspersed with enough insurance forms to minimize the impact. 
Internal medicine

A little gooier than family medicine. If you do not enjoy the tangy aroma of infectious diarrhea, stay away from this specialty.

\section{Pediatrics}

Patients are often very gooey and have not gained full goocontrol. However, they are relatively easy to tolerate because the goo has not had 75 years to fester.

\section{High-goo specialties (score 7-9)}

\section{All surgical specialties}

Surgery is perfect for those who like to be up to their elbows in goo. When goo gets explosive - think projectile vomiting, arterial spray, or tense, pus-filled abscesses - who do you think they're going to call? (Not the psychiatrist, I can assure you.)

Note: Be wary of surgical specialties such as ophthalmology that try to fool you by assigning pretty names to their goo, such as "aqueous humour" and "vitreous humour." Let's be honest: when a nail gun meets an eyeball, there is nothing humorous about it - it's just aqueous goo and vitreous goo.

\section{Emergency medicine}

This specialty is made worse by the fact that the goo is entirely unpredictable. The emergency physician can be relaxing with a Bratwurst sandwich one minute and picking someone's intestines off the floor the next.

\section{Dermatology}

This is a specialty for the true goo connoisseur. Dermatologists delight in taking photos of the gooiest lesions they can find, then presenting them in slide shows with catchy titles such as "Ior really cool penile warts."

\section{Extreme-goo specialties (score $\geq 10$ )}

\section{Pathology}

If festering abscesses and explosive melena are not gooey enough for you, this specialty is a perfect choice. Pathology is the only specialty where you get to work with decomposing, bug-infested goo and use words such as "putrefaction" and "necrosis." Plus you get to solve murders singlehandedly and hang out with all those hot-looking crime-scene investigators.

\section{Conclusion}

I believe that my Goo Tolerance Index will be a helpful tool for those of you facing the momentous decision of choosing a medical specialty. And may your gooiest memories of this holiday season be of turkey drippings, plum pudding and sloppy kisses under the mistletoe.

\section{Julie Curwin MD}

Psychiatrist

Sydney, NS 